\section{Case Reports in Ophthalmology}

Case Rep Ophthalmol 2018;9:167-171

DOI: $10.1159 / 000487077$

Published onlıne: March 2, 2018
(C) 2018 The Author(s)

Published by S. Karger AG, Basel www.karger.com/cop

This article is licensed under the Creative Commons Attribution-NonCommercial 4.0 International License (CC BY-NC) (http://www.karger.com/Services/OpenAccessLicense). Usage and distribution for commercial purposes requires written permission.

\title{
Posterior Wall Collapse in High Myopia following Cataract Surgery
}

\author{
Galia A. Deitz ${ }^{a} \quad$ Adam R. Sweeney $^{b} \quad$ Hoon C. Jung ${ }^{b, c}$ \\ ${ }^{a}$ University of Washington School of Medicine, Seattle, WA, USA; \\ ${ }^{b}$ University of Washington Department of Ophthalmology, Seattle, WA, USA; \\ ${ }^{c}$ Veterans Affairs Puget Sound Health Care System, Seattle, WA, USA
}

\section{Keywords}

Cataract surgery $\cdot$ High myopia $\cdot$ Hypotony $\cdot$ Suture removal

\begin{abstract}
Purpose: We report a case of posterior globe collapse of an eye after initial recovery from uncomplicated cataract surgery in a patient with high myopia and discuss the course of management involving recognition and emergent air injection with globe reformation. Case Report: A 64-year-old functionally monocular male with a history of high myopia presented for follow-up after uncomplicated cataract surgery. Uncorrected distance visual acuity (UCDVA) at postoperative day 1 was 20/150 with an intraocular pressure (IOP) of $19 \mathrm{~mm} \mathrm{Hg}$. At the week 1 visit, UCDVA had decreased to 20/200 with an IOP at $9 \mathrm{~mm} \mathrm{Hg}$. After preliminary exam, the keratome site suture was removed, after which the patient reported vision changes. A dilated fundus exam was performed revealing posterior scleral wall collapse. A clinical diagnosis of hypotony was made and a pars plana injection of $1 \mathrm{~mL}$ air was performed. This resulted in immediate subjective improvement of vision. Exam the next day revealed UCDVA 20/50 with pinhole improvement to 20/30 and IOP $15 \mathrm{~mm} \mathrm{Hg}$. Conclusion: This case demonstrates postoperative hypotony in a patient with pathologic myopia, following cataract surgery. Pathologically myopic eyes may have greater propensity to collapse in the setting of reduced IOP.

(C) 2018 The Author(s)

Published by S. Karger AG, Basel
\end{abstract}




\section{Case Reports in Ophthalmology}

Case Rep Ophthalmol 2018;9:167-171

DOI: $10.1159 / 000487077$

(C) 2018 The Author(s). Published by S. Karger AG, Basel www.karger.com/cop

Deitz et al.: Posterior Wall Collapse in High Myopia following Cataract Surgery

\section{Introduction}

Hypotony is typically associated with complications following glaucoma surgery and perforating eye injuries [1], but can occur as a consequence of any pathology causing a reduction in production, or increase in outflow, of aqueous humor. Hypotony has statistical and clinical definitions. Statistically, hypotony is an intraocular pressure (IOP) less than 6.5 $\mathrm{mm} \mathrm{Hg}$, which corresponds to more than three standard deviations below mean IOP. Clinically, hypotony is an IOP which is low enough to cause visual loss [2].

The most widely reported postoperative complications following cataract extraction with intraocular lens placement are: posterior capsular opacification, elevated IOP, corneal decompensation, cystoid macular edema, refractive surprise, and endophthalmitis [3]. While rare, postoperative hypotony after cataract extraction also can occur, and is most likely to occur in the context of a nonhealing, or leaking, cataract wound [4].

\section{Case Report}

A 64-year-old male was referred for surgical cataract treatment of the left eye. Ophthalmic history was complex and significant in the right eye for trauma (boxing and baseball injuries as youth) resulting in secondary traumatic glaucoma, cataract, and traumatic optic neuropathy. Numerous surgical treatments were performed 17 years prior to presentation, including 2 trabeculectomy surgeries, cataract extraction with intraocular lens implantation, and Nd:YAG laser for posterior capsular opacification (4 years prior to presentation). The right eye additionally had a history of endophthalmitis complicated by hypotony and subretinal fibrosis (7 years prior to presentation) and had a small central island of vision remaining from numerous pathologies. The left eye history was significant for high myopia optically corrected with a soft contact lens. By history, the patient used his left eye for essentially all tasks due to the constricted visual field and quality of vision of the right eye.

Best corrected visual acuity was $20 / 30$ and $20 / 60$ in the right and left eye, respectively. Refractive correction in diopters (dpt) was $+3.00 \mathrm{dpt}+1.00 \times 082$ with spectacles for the right eye and $-13.75+4.75 \times 085$ with a soft contact lens. A polycarbonate plano spectacle lens was used as protective eye wear for the left eye. A 4+ relative afferent pupillary defect for the right side was noted. Tonometry of the right eye was 7 and $18 \mathrm{~mm} \mathrm{Hg}$ for the left eye. Slit-lamp exam revealed a functioning superior bleb for the right eye, a posterior chamber intraocular lens (PCIOL) and surgical iridectomy site superiorly. Posterior exam of the right eye revealed significant glaucomatous cupping of the optic nerve and subretinal fibrosis. Left eye exam was significant for combined cataract with nuclear, cortical, and posterior subcapsular changes as well as myopic fundus changes. The left eye also appeared to be buphthalmic in association with its high axial length. After counseling of risks and benefits, consent for left eye cataract treatment was obtained and biometric measurements were taken after 2 weeks of a contact lens holiday. A refractive target of $-0.5 \mathrm{dpt}$ was set for the patient.

Uncomplicated cataract surgery and intraocular lens implantation for the left eye was performed with topical anesthesia. Of note was very poor dilation of the left pupil at about $4.5 \mathrm{~mm}$. Due to the functionally monocular status, a 10-0 nylon suture was used to close the keratome wound for additional wound closure during recovery. At the 1-day postoperative visit, the patient's uncorrected distance visual acuity (UCDVA) was 20/150 with pinholeassisted acuity of 20/60. Tonometry was $19 \mathrm{~mm} \mathrm{Hg}$ for the left eye. Anterior segment exam was significant for a tight-appearing 10-0 nylon suture at the keratome site, which was 


\section{Case Reports in Ophthalmology}

Case Rep Ophthalmol 2018;9:167-171

DOI: $10.1159 / 000487077$

(C) 2018 The Author(s). Published by S. Karger AG, Basel www.karger.com/cop

Deitz et al.: Posterior Wall Collapse in High Myopia following Cataract Surgery

Seidel negative, $1+$ cell and flare in the anterior chamber, and an appropriately centered PCIOL. The patient was prescribed a regimen of postoperative topical anti-inflammatory and antibiotic eye drops with follow-up recommended for 1 week. At the following 1-week visit, the patient reported no issues, but minimal improvement of vision. UCDVA was 20/200 improving to 20/150 with pinhole assistance. Inflammation had reduced to trace cell and flare with a deep anterior segment and centered PCIOL. IOP was measured at $9 \mathrm{~mm} \mathrm{Hg}$ by tonometry. Clinical judgement was made to remove the 10-0 nylon suture, after which the patient reported vision changes. A dilated fundus exam was performed revealing posterior scleral wall collapse (Fig. 1) in the context of clinical hypotony. Urgent measures were put in place and $1 \mathrm{~mL}$ of filtered air was injected at the pars plana in the inferior temporal quadrant for volumetric replacement in the eye. The patient reported an immediate subjective improvement in vision and resolution of the globe collapse with indirect ophthalmoscopy. Postinjection pressure was measured at $10 \mathrm{~mm} \mathrm{Hg}$. Topical antibiotics and a bandage contact lens were utilized in addition to the topical anti-inflammatory eye drops. The next day exam revealed uncorrected visual acuity of 20/50 with improvement to 20/30 with pinhole. The IOP was measured at $15 \mathrm{~mm} \mathrm{Hg}$ over the contact lens. Anterior exam revealed a formed chamber with a centered PCIOL and posterior exam revealed a 50\% remnant air bubble, flat retina, and formed globe. Examination at 1 week postinjection revealed complete resorption of the air bubble and stable eye exam findings with UCDVA stabilized at 20/40 uncorrected and IOP of $18 \mathrm{~mm} \mathrm{Hg}$ over the bandage contact lens (Fig. 2).

\section{Discussion}

As a pathologic myope (spherical equivalent $>6.00 \mathrm{dpt}$ or axial length $>26.5 \mathrm{~mm}$ ) the patient presented in this case report is part of a population known to have unique risks following cataract surgery. Most notably, eyes with a high degree of myopia may be more likely to develop retinal detachment and residual refractive error in the postoperative period following cataract extraction with intraocular lens replacement [5]. Though there are no recognized large associations between pathologic myopia and postoperative hypotony following cataract surgery, it has been thought that the thinner, less rigid sclera of a myopic eye may be more likely to collapse in the setting of reduced IOP [6].

The mechanism of posterior wall collapse in the absence of a shallow anterior chamber presents a mechanistic challenge. There may be regional susceptibility of the posterior globe to collapse in certain pathologies, but how that related to manipulation of the anterior segment remains unknown in this case. Hypotony and globe collapse have been reported post retinal surgery; however, it is less likely an anticipated entity after cataract surgery [7]. It is possible that posterior globe collapse existed prior to suture removal attempts given the 10point differential on IOP from the 1-day and 1-week applanation. Either scenario likely warrants a dilated exam given the subpar vision at 1 week and considerations that suture removal could induce clinical hypotony in specific clinical settings.

\section{Acknowledgements}

Work to present this case report is supported by an unrestricted grant from the Research to Prevent Blindness (RPB). 


\section{Statement of Ethics}

Patient consent was obtained. No personally identifiable information is otherwise included in this case report.

\section{Disclosure Statement}

The authors have no conflicts of interest or proprietary interest in any of the topics or products presented in this case report.

\section{References}

1 Costa VP, Arcieri ES: Hypotony maculopathy. Acta Ophthalmol Scand 2007;85:586-597.

2 Pederson JE: Ocular hypotony; in Ritch R, Shields MB, Krupin T (eds): The Glaucomas. St. Louis, Mosby, 1996, pp 385-395.

3 Chan E, Mahroo OAR, Spalton DJ: Complications of cataract surgery. Clin Exp Optom 2010;93:379-389.

$4 \quad$ Meszaros L: How low is too low? Ophthalmology Times. July 2013.

5 Dodick JM, Kahn JB: Special considerations for cataract surgery in the face of pathologic myopia; in Spaide RF, Ohno-Matsui K, Yannuzzi LA (eds): Pathologic Myopia. New York, NY, Springer Science + Business Media, 2014, pp 313-314.

6 Gass JD: Hypotony maculopathy; in Bellows JG (eds): Contemporary Ophthalmology. Honoring Sir Stewart Duke-Elder. Baltimore, Williams \& Wilkins, 1972, pp 343-366.

7 Schoenberger SD, Riemann CD: Profound postoperative hypotony with globe collapse after 25-gauge pars plana vitrectomy. Retina Cases Brief Rep 2012;6:415-418.

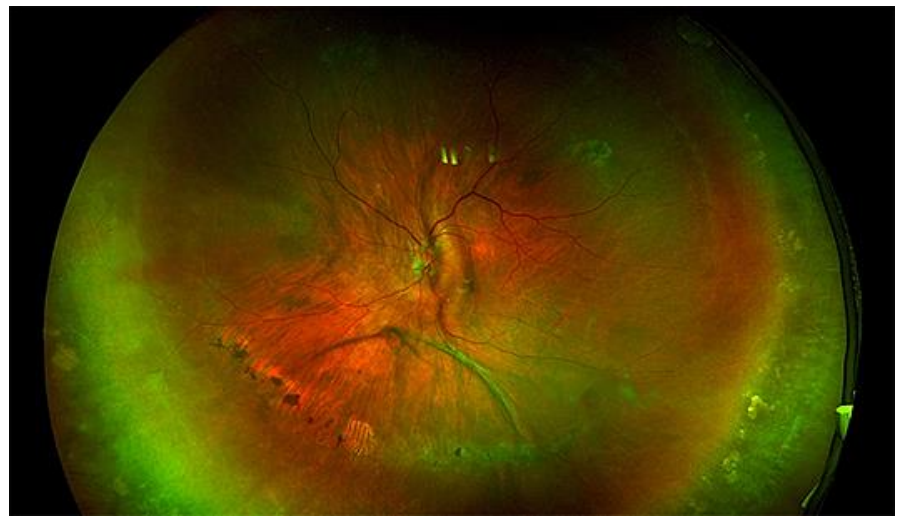

Fig. 1. Fundus photo after removal of corneal suture prior to injection of air. 


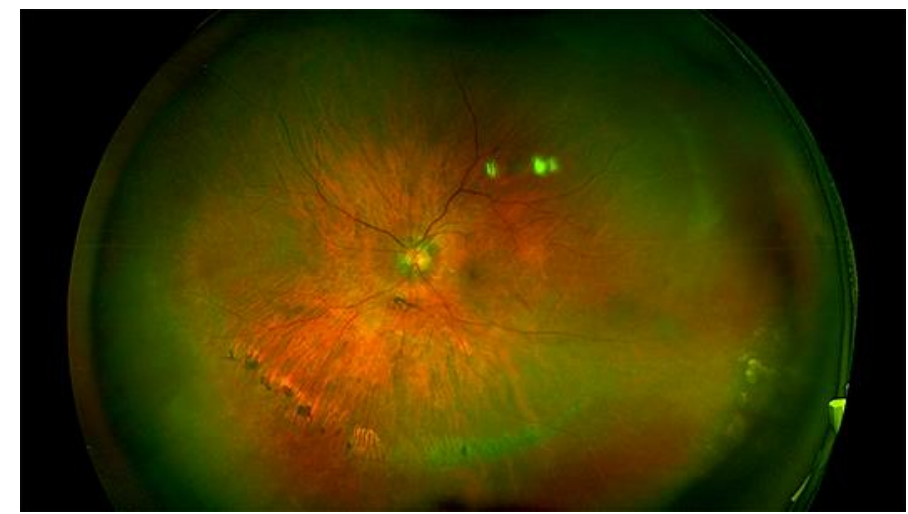

Fig. 2. Fundus photo 1 week after air injection and resorption of air bubble. 